\title{
Identifying Differences in the Level of Environmental Awareness among Male Students: A Case of Lower Elementary Grades
}

\author{
Imad Tawfiq Sa'di \\ Associate Professor at Faculty of Education \\ Yarmouk University, Irbid, Jordan
}

\begin{abstract}
Some students in the first three grades interact with undesirable stimuli or models that may harm the environment, particularly in multi-cultural societies such as Makkah Al-Mukarramah. There are many obstacles that hinder the international and national initiatives related to the environmental issues and to the inclusion of an environmental dimension in the school curriculum, one of which is the ineffective employment of measurable means of creating and developing environmental awareness. Therefore, the present study aims to develop and validate an environmental awareness scale with acceptable psychometric properties. The study also investigates the level of environmental awareness of students in the first three grades and determines whether it differs significantly based on the grade level. The study sample entailed 45 male students from the first three grades at Makkah Al-Mukarramah schools, who showed a moderate level of environmental awareness. The results showed that Saudi students in the first three grades are aware that the environment is suffering from people's behaviours. The students might have been affected by the general atmosphere in Makkah Al-Mukarramah and the principles of Islam that give high consideration to environmental issues and motivated people to manage their environmental behaviours. The study results have concluded that there is a significant difference in the students' level of awareness based on their grade level and; therefore, more emphasis is needed on environmental issues to raise their awareness to a high level.
\end{abstract}

Keywords: Environmental Awareness; First Grades; Awareness Scales; Elementary School.

\section{Introduction}

The environmental issues including global warming, flooding, desert encroachment, and depletion of ozone layer are of a major concern for the whole world. The causes of the environmental problem are associated with different 
patterns of production by the industries and patterns of consumption by the consumers (AhmadIsiyaka et al., 2014). It is important for the individuals to preserve and protect the environment through the development of new forms of skills, behaviour, and attitude at an early age. Rapid scientific and technological development has contributed to dramatic changes in people's environmental activities; therefore addressing such problems requires modifying human behaviour and awareness (Ryan \& Spash, 2012).

The purpose of discussing the environmental issues with the elementary school students is to make them aware of the current ecological problems and the methods that could be adopted to overcome such problems. For instance, it has been determined that at present, Saudi Arbia is encountering some environmental harms (Alzahrani, 2009; Alutaibi, 2006; Alutaibi, 2003; Hameed, 2003; Ba-Boteen, 2002). Hence, environmental education is important at all study levels, mainly the early stages, to develop students' awareness and enhance their positive environmental behaviours (Shernoff et al., 2016; Uzun, \& Keles, 2012). The environmental education for the students in the elementary schools does not seem to be restricted to the provision of information, rather these schools are involved in developing the behaviour of students regarding the protection of environment (Huang, Chen, \& Chou, 2016). For this purpose, different environmental programmes have been developed in different schools that enable the students to discuss environmental problems and problem-solving methods (Sáez-López, Román-González, \& Vázquez-Cano, 2016). Since the environmental problems are increasing day by day, it is important to seek new approaches that could help reduce the degree of environmental crisis (Reed, Van Vianen, Deakin, Barlow, \& Sunderland, 2016).

Students in lower elementary grades interact with undesirable stimuli or models that may harm the environment and that fail to pay attention to and/or respect its balance (Kelder, Hoelscher, \& Perry, 2015). Therefore, the students can recognize and address environmental issues such as littering, water wastage, electricity, pollution; using chemical sprays, cutting plants, using cars instead of buses, eating junk food, and writing on school walls, and public property (Ali, Endut, \& Embong, 2017). However, there are many obstacles that hinder the international and national initiatives related to the environmental issues and to the inclusion of an environmental dimension in the school curriculum, one of which is the ineffective employment of measurable means of creating and developing environmental awareness (Goodall, 2018). Investigating environmental awareness among elementary school students is a fundamental goal for educators to develop environmentally aware students who act responsibly to provide a foundation for productive behaviour and its future impact. Globally, it can be seen that not all elementary schools are able to address the adequate knowledge and understanding of environment and environmental degradation to the students. However, it is one of the most important topics that must be considered in almost all areas.

The majority of the previous studies have focused on knowledge and understanding of environmental problems as the only aspects leading to 
awareness. However, the consequences of behaviours and the ability to predict these consequences are given minimum importance. Limited studies have been conducted regarding the impact of formal environmental education on the environmental awareness of students in the first three grades, which is considered as the most important stage in a student's life for the formation of future environmental behaviour. The same trend was found throughout the Arab world and in Saudi Arabia as majority of the studies conducted in Saudi Arabia have addressed the environmental awareness of teachers and high school or university students (Ba-Boteen, 2002; Hameed, 2003; Alutaibi, 2006; Alzahrani, 2009; Ali et al., 2017). Therefore, the present study aims to develop and validate an environmental awareness scale with acceptable psychometric properties. The study also investigates the level of environmental awareness of students in the first three grades and determines whether it differs significantly based on their grade level. To achieve the aims of the study, it attempted answering the following questions:

1. Does the environmental awareness scale developed in this study have acceptable psychometric properties?

2. What is the level of environmental awareness among students in the first three grades?

3. Does the level of environmental awareness among students in the first three grades differ significantly by grade level (first, second or third)?

\section{Literature Review}

The Oxford Dictionary (2013) defines awareness as knowing something or knowing that something exists and is important. It means having knowledge or understanding about a particular thing. There is a need to provide a clear definition of awareness that differentiates it from knowledge and understanding (knowing how to behave) definitions, derived from Skinner's work in behavioural science asserting that behaviour is governed by its consequences (Leigland, 2011). Hence, awareness may be defined as knowing both the consequences of behaviours or events in addition to knowing how to behave. A previous study conducted by Komane (2005) emphasized that environmental education fosters awareness, values, and attitudes that support the proper use of the earth's resources and the protection and improvement of the earth for present and future generations.

The impetus to focus on the environment began in the 1970s after the establishment of an international environmental education programme recommended by the UN Conference on the Human Environment held in Stockholm in 1972 (Ali et al., 2017). This recommendation was followed by outlining the basic goals of environmental education in Belgrade in 1975 and was reinforced in 1977 in Tbilisi that was the most important conference conducted and sponsored by UNESCO. Tbilisi conference was considered as the cornerstone of environmental education (Subbarini, 1989). Delegates ratified the definition of environmental education as a process of developing a world population that is aware of and concerned about the total environment and its associated problems (Braus \& Wood, 1993). The three main goals presented in 
the final report of the Tbilisi conference were to foster clear awareness of and concern about, economic, social, political and ecological interdependence in urban and rural areas (UNESCO, 1978).

Based on the final report of the Tbilisi conference, awareness can be understood as helping students to acquire sensitivity to the total environment and its allied problems to develop their ability to perceive and discriminate among stimuli, processing, and refining. These perceptions are likely to be extended and used in a variety of environmental contexts (Akbasli \& Meydan, 2010). Childhood is considered as an important stage of life as the individuals begin learning the standards of their family and society that will form the foundation of their future behaviour in the natural, artificial, and social environments. There is a different impact of environmental issues on the children and adults because environmental contaminants pose a greater risk to children than to adults as they grow. Therefore, improving and protecting the environment and preventing pollution are the duty of all governments and peoples, including children who have been taught to be environmentally aware (Akbasli \& Meydan, 2010; Maravić, Cvjetićanin \& Ivković, 2014).

Abolaji, Oke, and Adebanjo (2011) investigated the awareness, knowledge, and understanding of 250 students in a study conducted in London. Their results indicated a relatively low level of understanding of environmental concepts despite the efforts of government and environmental agencies to promote awareness about environmental issues outside of school. These results confirmed that an environmentally based school curriculum plays a major role in promoting students' understanding of environmental concepts, awareness of major environmental issues, and positive attitudes towards the natural environment. Moreover, the results of Barhoum (2012) recommended raising environmental awareness among elementary school students by including environmental problems in the school curriculum and including teachers in the development of students' environmental awareness.

Similar results were obtained by Singseewo (2011) who noted that students were clearly inefficient in analysing the effects of human activities on the environment. Therefore, the students were unable to introduce appropriate practices for conserving natural resources and protecting the environment. This showed that schools lack the ability to promote students' environmental recognition and awareness of environmental issues. Alzahrani (2009) supported this result by reporting that secondary students had a moderate level of awareness of the dangers of electronic waste. A similar result was found by Alutaibi (2006), who noted that the level of student awareness towards the risks of environmental pollution among Saudi women in Riyadh was low.

There is a significant increase in the environmental issues; therefore, the students need to build environmental attitudes through the system of environmental protection (Uzin \& Keles, 2012). A similar study was conducted by Horka and Markova (2013) stated that education plays an important role in shaping the attitudes and behaviours of individuals as it helps in determining 
the social and economic development in accordance with sustainable development. A recent study by Ali et al. (2017) conducted a survey method by recruiting 1200 students. The results showed that the majority of the students had low level of environmental awareness with significant difference in the environmental awareness level of students at three different levels and consequences. On the contrary, Altin, Tecer, Tecer, Altin, and Kahraman (2014) showed increased level of environmental awareness among participant students.

Besides, Bergman (2016) showed evidence that teacher education is required in order to address appropriate environmental education to the students. However, the study further found that the teachers in the elementary schools possess the knowledge regarding the soil, water, air pollution as well as greenhouse effect but are found uninvolved in providing the opinions on protecting the environment. Conveying inadequate information is the ultimate cause of environmental crisis worldwide. Thus, Bergman's study concluded that an inefficient achievement could be seen in the pupil's attitudes towards the environmental issues.

Accordingly, Mwendwa (2017) determined that the students studying in Tanzania's elementary schools lack the knowledge and awareness regarding the ecological problems and are unable to propose ideas that could assist in minimizing some important environmental issues. This is because the teachers in Tanzania schools are found to have challenges in the teaching of environmental education due to inadequate resources, class size and time. However, it is important for the authorities of the elementary schools to take into consideration the importance of environmental education and take active participation in organizing sessions in the schools in order to influence students behave pro-environmentally.

Hammami et al, (2017) conducted a study emphasizing on environmental knowledge, attitudes and behaviour of elementary students specifically male students in Sharjah. The study determined that most of the male students have shown positive attitudes towards the environment and its crisis. Green programmes arranged by the elementary schools have also contributed in increasing the students' environmental knowledge. However, such programmes are identified to be inappropriate in influencing the students' environmental behaviour adoption. Male students have actively participated in the recycling activities arranged through the green programme but they have shown lack of interest in proposing their views for minimizing the severity of environmental crisis globally.

While, Kodama, (2017) indicated that the male students in the elementary schools located in Japan are more concerned with the environmental humiliation. These students believe that it is essential to overcome environmental issues in order to maintain the healthy life-style and thus decrease the morbidity ratio in the country. These students are found to have contributed to the causalities of environmental humiliation. The adequate 
knowledge and appropriate behavioural adopting methods are important to drive the attention of students towards the environmental degradation.

\section{Methodology}

3.1. Study Design

A survey was conducted among the primary school children from grade 1, 2, and 3 in Saudi Arabia. The study was conducted between September and December, 2017.

\subsection{Study Sample}

The study participants were selected from boys' schools in Makkah AlMukarramah city. The population of the study comprised 296 schools, including 573 first grade sections consisting of 11,511 students, 519 second grade sections consisting of 11,356 students, and 527 third grade sections consisting of 11,242 students. The participants in the study were an available sample that consisted of 60 students serving as a pilot sample, 20 students from each class level and 45 students from three elementary schools in Makkah Al-Mukarramah city. The participants who formed the study sample ranged in age from 6-9 years old. They were chosen from the first, second, and third grades (15 each) and were taught by the research assistants. The study has not considered a wide and random sample from this population due to inopportuneness conditions. M.A. and B.A. university students helped in conducting the study to facilitate its implementation. The volunteering students had regular meetings with the researcher and were given detailed instructions and training regarding the implementation of the environmental awareness scale. The volunteers were encouraged to be neutral and were informed that the study was being conducted for scientific purposes only.

\subsection{Ethical Consideration}

The researcher had permission to implement the study from the general directorate of education in Makkah Al-Mukarramah. Consent from the parents was obtained before enrolling their children in the study.

\subsection{Research Instrument}

A significant number of previous studies were reviewed to measure environmental awareness among students in the first three grades (Cohen \& Wingerd, 1993; Musser \& Malkus, 1994; Leeming, Dwyer \& Bracken. 1995; Reid \& Sa' di, 1997; Musser \& Diamond, 1999; Ryan \& Spash, 2012). The present study has developed an environmental awareness scale for lower elementary school students that could be administered in a short time and did not depend on their ability to read or write, which might have led to invalid results for students in this early stage. Therefore, a scale that depends on pictures seemed to be the best option for students in the lower elementary classes. Moreover, the scale was environmentally friendly as it was administered to the students through a computer or a smart phone that guaranteed the clarity and colour of the pictures. 
The scale items for the questionnaire were based on twelve sets of pictures depicting environmental events (pollution, waste, and conservation). Each set contained three pictures, one was used as a stimulus picture and two expressed the expected and appropriate consequences of the events in the stimulus picture. The student was asked to re-arrange the two pictures, which were arranged randomly, depending on the stimulus picture. The students were presented with the stimulus picture by the teacher, who was trained to administer the scale by asking a simple question related to the stimulus ("Which picture comes first (or next)?") and then asking the students to re-arrange the two pictures by pointing to the likely outcome of the two possibilities depicted in the pictures on the screen. Table 1 shows an example of the scale items (sets of the scale).

Table 1: An Example of the Environmental Awareness Scale ${ }^{1}$ Items

\begin{tabular}{llll}
\hline No & Stimulus picture & \multicolumn{2}{c}{ Consequences } \\
\cline { 3 - 5 } & & Appropriate & Inappropriate \\
\hline 8 & & & \\
& & &
\end{tabular}

\subsection{Data Collection}

The students' responses were recorded on an answer sheet. The students were informed that they could continue to the next question if they did not want to answer or if they had difficulty making a selection after they were shown a stimulus picture. Each set of pictures was assigned a numerical score ranging from 1-3 (a 1-to-3 rating scale). The students received a score of 3 if they selected the picture that should immediately follow the stimulus picture, indicating that they were aware of the appropriate consequences of what was depicted in the stimulus picture. They received a score of 2 if they chose to remain neutral and not select a picture or a score of 1 if they selected the inappropriate picture first. The maximum score that a student could obtain on the final version of the scale (10 items) was 30, and the minimum was 10 . The maximum time for each student to re-arrange the 10 sets of pictures was not to exceed 15 minutes.

\section{Results}

Does the environmental awareness scale developed in this study have acceptable psychometric properties?

Ten items (10 sets of pictures) were used for creating and formatting the scale to examine the environmental awareness level of students in the first three grades using the environmental awareness definition and the environmental concepts and their related subjects.

\footnotetext{
${ }^{1}$ To be requested from the author if needed.
} 


\subsection{Scale Validity}

The researcher constructed the Environmental Awareness Scale for students in the first three grades considering the students' time and attention constraints and their language ability at this age. The scale was designed to be adaptable for worldwide use regardless of students' language and grade level, particularly in the lower elementary grades. Twelve items containing 36 pictures related to the environmental concepts of pollution, waste, and conservation were constructed because pictures can be considered as a universal language. The pictures were distributed along with the scale's aims and instructions to fourteen experts in the fields of elementary education, science education, measurement, and evaluation. The experts were asked to assess the scale's scoring rule (3 points for the appropriate consequence, 2 for the neutral response, and 1 point for the inappropriate response), suitability, and clarity for students in the first three grades. Additionally, the experts were asked to determine the scale's face validity and the statistical criterion used to rate students' level of awareness as high, moderate, or low. A mean score of 2.34-3 was considered high, 1.67-2.33 was moderate, and 1-1.66 was low.

All of the experts agreed that the scale items measured environmental awareness among students in the first three grades. However, they commented on some scale items $(4,5,10)$, requesting more expression and clearer pictures and those items were modified. For example, item 4 was changed to represent "car litter" instead of a "child throwing a piece of paper on the ground". Item 5 was modified to express the "formal dress of a scavenger in Makkah Al-Mukarramah with his green colour and his special cleaning tools" instead of a scavenger from another culture "picking litter from a street". However, the stimulus picture in item 10 was changed to show "a hunter" instead of "a hunting dog", which expressed a culture other than the Saudi one.

\subsection{Scale Reliability}

The scale was administered to a pilot sample $(\mathrm{N}=60)$ of first, second, and third grade students. For the final version of the scale, a two-step process was used to select an item. First, the item-total correlation was calculated for each item to examine the discriminative validity or the construct validity of the scale. Second, Cronbach's alpha was used as a measure of internal-consistency reliability. The scale showed excellent psychometric properties, as shown in Table 2. Table 2 has shown that the item-total correlation ranged from -0.24 to 0.14 ; whereas, the means ranged from 1.43 to 2.38 with a standard deviation of 0.79 to 0.99 . Cronbach's alpha for the 12-item scale was 0.79. All the scale items had good values except two (item 2 and item 7). Item 2 had a negative value for the corrected item-total correlation (-0.242); whereas, item 7 had a low value (0.136). The two items were deleted based on the above mentioned criteria. However, the two items had extreme means and their deletion would increase the variability of the scale. This indicated that every student answered the questions almost the same way, which ensured that the deletion of the two items would improve the scale's psychometric properties. Thus, the remaining items (10 items) were selected for the final version of the scale and provided a good representation of environmental awareness. 
Table 2: Psychometric Properties of the Environmental Awareness Scale

\begin{tabular}{cccccc}
\hline Item & Mean & $\begin{array}{c}\text { Standard } \\
\text { deviation }\end{array}$ & $\begin{array}{c}\text { Corrected } \\
\text { item-total } \\
\text { correlation }\end{array}$ & $\begin{array}{c}\text { Scale variance } \\
\text { if item } \\
\text { deleted }\end{array}$ & $\begin{array}{c}\text { Cronbach's } \\
\text { Alpha if item } \\
\text { deleted }\end{array}$ \\
\hline 1 & 2.1500 & .97120 & .454 & 32.706 & .775 \\
2 & 2.3833 & .80447 & -.242 & 40.518 & .830 \\
3 & 2.0500 & .96419 & .574 & 31.547 & .763 \\
4 & 2.0333 & .99092 & .590 & 31.182 & .761 \\
5 & 2.1333 & .98233 & .420 & 32.989 & .779 \\
6 & 2.1500 & .97120 & .643 & 30.808 & .755 \\
7 & 1.4333 & .78905 & .136 & 36.762 & .801 \\
8 & 2.1667 & .95964 & .348 & 33.880 & .786 \\
9 & 2.3000 & .94421 & .595 & 31.492 & .761 \\
10 & 2.2000 & .95314 & .603 & 31.346 & .760 \\
11 & 2.1833 & .94764 & .645 & 30.986 & .755 \\
12 & 2.1167 & .97584 & .397 & 33.271 & .781 \\
\multicolumn{7}{l}{ Cronbach's alpha } & .792 & & & \\
\hline
\end{tabular}

The students' responses to the 10 remaining items were calculated, considering that a greater number of scale items would produce a higher coefficient of reliability. The 10 items yielded an excellent Cronbach's alpha coefficient (0.84). The item-total correlation ranged from 0.37 to 0.62 , the means ranged from 2.11 to 2.30 ) and the standard deviation ranged from 0.94 to 0.99 . Therefore, all items had positive values for the corrected item-total correlation. It was assumed that the scale had good psychometric properties and could be used for the purposes of this study. The Cronbach's alpha coefficient was calculated after the administration of the scale to the study sample $(\mathrm{N}=45)$ to support the results and examine this assumption. An analysis of their responses showed that the corrected item-total correlation ranged from 0.27 to 0.54 , and the alpha reliability coefficient was 0.775 . Furthermore, data were recorded by both the classroom teacher and a student-teacher attending the session throughout the datacollection stage. The results were found to be $100 \%$ compatible, which indicated that the environmental awareness scale was valid and reliable and could be administered to the sample of the study.

What is the level of environmental awareness among students in the first three grades?

The means and standard deviations for each item, grade level, and total score of the scale were calculated to answer the second question. Table 3 has shown the descriptive data of the study sample $(\mathrm{N}=45)$ for each item and the total score for the scale. The means of the items ranged from 1.96 to 2.40 , with a standard deviation of 0.84 to 0.98 . The same Table showed that the mean of the total items of the scale was 21.58 with a standard deviation of 5.37, which indicated a moderate level of environmental awareness. It is apparent in the table that the score on 9 out of 10 items was moderate. This result reveals that Saudi students in the first three grades are aware that the environment is suffering from people's behaviours. These students may have been exposed to school subjects regarding the environment that addressed environmental problems and environmentally friendly behaviours. It should also be noted that Makkah Al- 
Mukarramah (where the students in the study sample lived and studied), is considered the holiest place on earth by Muslims. Therefore, the students might have been affected by the general atmosphere in Makkah Al-Mukarramah and the principles of Islam that give high consideration to environmental issues and motivate people to manage their environmental behaviours. Nevertheless, this moderate level of environmental awareness is insufficient. The students need more emphasis on environmental issues to raise their awareness to a high level.

Table 3: The Means and Standard Deviations of the Study Sample

\begin{tabular}{cccccc}
\hline No. & Rank & Mean & $\begin{array}{c}\text { Standard. } \\
\text { deviation }\end{array}$ & $\begin{array}{c}\text { Awareness } \\
\text { level }\end{array}$ & $\begin{array}{c}\text { Environmental } \\
\text { concept }\end{array}$ \\
\hline 1 & 6 & 2.08 & .97 & Moderate & Pollution \\
2 & 10 & 1.96 & .95 & Moderate & Conservation \\
3 & 8 & 2.07 & .94 & Moderate & Waste \\
4 & 6 & 2.08 & .92 & Moderate & Pollution \\
5 & 5 & 2.11 & .96 & Moderate & Pollution \\
6 & 1 & 2.40 & .84 & High & Pollution \\
7 & 9 & 2.04 & .98 & Moderate & Conservation \\
8 & 2 & 2.31 & .95 & Moderate & Pollution \\
9 & 4 & 2.24 & .91 & Moderate & Waste \\
10 & 3 & 2.27 & .91 & Moderate & Pollution \\
Total & & $\mathbf{2 1 . 5 8}$ & $\mathbf{5 . 3 7}$ & Moderate & \\
\hline
\end{tabular}

Does the level of environmental awareness among students in the first three grades differ significantly by grade level (first, second or third)?

The means and standard deviations for each grade level were calculated to answer the third research question. Table 4 has shown the means and standard deviations for the total scores of the students by grade level. The mean total score for the first grade students was 19.00 with a standard deviation of 5.39; whereas, the mean total score for the second grade students was 21.93 with a standard deviation of 4.68 . For the third grade students, the mean total score was 23.80 with a standard deviation of 5.21. These results indicated that the third grade students had a higher level of environmental awareness than the second grade or first grade students; whereas, the second grade students had a higher level of environmental awareness than the first grade students.

Table 4: The Means and Standard Deviations of the Study Sample by Grade Level

\begin{tabular}{lllc}
\hline Grade & $\mathbf{N}$ & Mean & Std. Deviation \\
\hline First & 15 & 19.00 & 5.39 \\
Second & 15 & 21.93 & 4.68 \\
Third & 15 & 23.80 & 5.21 \\
Total & $\mathbf{4 5}$ & $\mathbf{2 1 . 5 8}$ & $\mathbf{5 . 3 7}$ \\
\hline
\end{tabular}

The $F$ value $[F(2,42)=3.374]$ indicated that the differences between the means of the three groups of students were statistically significant at $(\alpha=.05)$, indicating statistically significant differences among the students' total environmental awareness scores by grade level. These results were based on the results of the 
one-way ANOVA of the total scores for the students' level of environmental awareness (Table 5).

Table 5: One-Way ANOVA of the Total Scores of the Study Sample by Grade Level

\begin{tabular}{lccccr}
\hline Source of Variance & Sum of Squares & Df & Mean Square & F & Sig. \\
\hline Between Groups & 175.644 & 2 & 87.822 & 3.374 & .044 \\
Within Groups & 1093.333 & 42 & 26.032 & & \\
Total & 1268.978 & 44 & & & \\
\hline
\end{tabular}

A post hoc test was conducted to determine the sources of the results for the three grade levels shown in Table 5 above. T-test was utilized to examine the differences between the means of the three grade levels at significance level of $(\alpha=.05$.) Table 6 shows that the differences between the means of the environmental awareness levels for the first grade students and the second grade students and for the second grade students and the third grade students were not significant. The only significant difference was between the means of the first grade students and the third grade students. These results indicate that most of the observed differences between the means of the students' environmental awareness were due to chances.

Table 6: T-Test for the Mean Differences by Grade Level

\begin{tabular}{llccc}
\hline Class & & Mean Difference & Std. Error & Sig. \\
\hline First & Second & -2.93 & 1.84253 & .318 \\
& Third & -4.80 & 1.93514 & .056 \\
Second & Third & -1.87 & 1.80915 & .664 \\
\hline
\end{tabular}

The significant difference that was shown by the ANOVA reported in Table 5 can be attributed to the difference between the mean scores of the first grade students and the third grade students $(-4.80)$. These results may be related to the fact that age had less of an effect on the second grade students; although, third grade students are more mature than first grade students due to age factors. Moreover, the difference between the second grade students and the first and third grade students was less pronounced. Therefore, the difference in the second graders' mean of environmental awareness scores and those of the other two groups of students was not significant.

\section{Discussion}

The present study was conducted in compliance with the recommendations and purposes of international environmental conferences, workshops and studies, and the goals of the United Nations initiatives and environmental programmes. The results are likely to help in bridging the gap in environmental studies with respect to lower educational levels. It has provided basic information and knowledge regarding the efficiency of formal teaching in Saudi Arabia to improve the environmental awareness of elementary school students by offering them more opportunities to analyse, criticize, and gain knowledge to efficiently 
address future environmental constraints and challenges. Moreover, the curriculum designers and educational decision makers may benefit from this study through greater awareness of the curriculum outcomes.

Environmental awareness is the gateway to all other aims, significantly the aim of environmental education in schools (Awan \& Wamiq, 2016). Most of the governments across the globe are motivated through the calls of environmental campaigns to reform their educational curricula. This reformation would help in achieving the aims of protecting the environment, conserving its natural resources, and reducing the degree of serious threat. This reformed curriculum, known as "environmental education" issued an interdisciplinary approach that integrated elements of nature and environmental studies into the basic objectives of elementary school subjects in Saudi Arabia and other Arab countries, particularly in the Gulf States. It has been shown that these countries focus on environmental issues with special concern for sustainable development (Alutaibi, 2006; Alfardan, 2007; Alzahrani, 2009; Maravić et al., 2014; Altin et al., 2014; Ali et al., 2017).

In the present study, the item addressing car litter, showed a high level of environmental awareness. This might be due to the fact that this behaviour is observed most often by students; whereas, other behaviours are observed less often. For instance, students can see people littering from their cars every day, but they may not see hunting behaviours. It appears that the students were familiar with some environmental behaviour and that they had the highest mean scores on the items they recognized. This may be why item 2 had the lowest mean (1.69) as the students were unfamiliar with recycling behaviours. The result of the second question disagreed with majority of the previous studies particularly in Saudi Arabia and the Gulf area (Alzahrani, 2009; Alfardan, 2007; Alutaibi, 2003; Ba-Boteen, 2002). This discrepancy might be related to the students' level of study and stage of development since most of the reviewed studies were conducted at different levels of study and with older students. It is well known that students in the early stages of education are affected by their teachers and follow their instructions more rigorously than do older students or adults.

In the present study, the second-grade students were in an intermediate stage between the third and the first-grade students. Therefore, their characteristics were similar to those of the other two groups as some second graders are in the operational stage of intellectual development, similar to the third graders. However, Mcgonigle-Chalmers (2015) noted that students from different grades may be still in the pre-operational stage, like first grade students. Additionally, the slight differences between the means of the three groups of students can be related to grade level because the curriculum in Saudi Arabia in the first three grades is spirally structured and presented.

In congruence with the present study, Johnston (2012) stated that even the most complex material can be understood by very young children, if properly 
structured and presented. However, three key features of spiral curriculum need to be considered including:

- the information is reinforced and solidified each time the student revisits the subject matter

- a logical progression from simplistic ideas to complicated ideas is allowed

- students are encouraged to apply early knowledge to later course objectives.

The generalization of the results of the present study is limited because the sample consisted only of students from Makkah Al-Mukarramah city in Saudi Arabia. Therefore, the results cannot be generalized to students in all Saudi schools. The sample included male students in the first three grades only so the results cannot be generalized to female students or other grade levels. Moreover, the study investigated environmental awareness using some environmental concepts. Therefore, the results cannot be generalized to represent environmental awareness of other concepts. The study was conducted by classroom teachers and the results may depend on the teachers' honesty and their degree of bias.

\section{Conclusion}

The present study has developed and validated environmental awareness scale with acceptable psychometric properties. The study also investigated the level of environmental awareness of students in the first three grades and determines whether it differs significantly based on the grade level. The results showed that majority of the third grade students are categorized as having a moderate level of environmental awareness. These students need to learn even more about the environment and its problems through a student-centred paradigm. This could be accomplished by focusing on a curriculum that reflects new practices and responds to the cognitive, social, and emotional needs of the students as well as one that can develop the student as an environmental thinker, a constructor, and a creator. Moreover, it is necessary to create initiatives that support a high level of environmental awareness that exposes students to specific environmental programmes that address environmental issues to achieve the ultimate goal of environmental education. This will help them to be more interested and engaged in environmental activities with respect to their developmental characteristics.

In spite of the moderate level of environmental awareness among Saudi elementary school students, they need to improve their environmental vision and their understanding of behavioural consequences to become more environmentally aware. This can be accomplished by designing student-centred environmental activities that can be delivered and implemented by providing students with hands-on environmental experiences and diverse learning resources and by offering them an attractive and reinforcing learning atmosphere. For example, planting small trees in the courtyard of the school to ascertain that friendly environmentally acts have no obstacles, collecting and saving trees during the entire school year, collecting recyclable waste materials which stimulates students and brings awareness to them to become active participants in cleaning up the school environment and conserving its resourcing by reusing waste, and meeting with nature through outdoor activities 
and a walk in the Makkah Al-Mukarramah city to observe the suffering surroundings, they could see pollutants that damage the nature.

Future studies need to be conducted in order to evaluate Saudi elementary school students' environmental awareness considering gender, family income, and school sector; although, the present study has provided a good indication of the environmental awareness level of students in the first three grades and the psychometric properties of the environmental awareness scale for elementary school children. Moreover, a wide range of participants is needed to gather data and further develop the awareness scale.

\section{References}

Abolaji, M., Oke, O., \& Adebanjo, A. (2011). An investigation of environmental education knowledge for sustainable development in high school sectors in UK. Journal of Life Sciences 5, 670-675.

AhmadIsiyaka, H., Juahir, H., Toriman, M. E., Gasim, B. M., Azid, A., Amri, M. K., \& Garba, M. A. (2014). Spatial assessment of air pollution index using environ metric modeling techniques. Advances in Environmental Biology, 8(24), 244-256.

Akbasli, S., \& Meydan, A. (2010). An evaluation of the problems of solid wastes at elementary schools depending on the views of school administrators. Education, 131(2), 407- 418.

Alfardan, N. (2007). The environmental awareness of primary school students in light of current environmental problems that confronting the kingdom of Bahrain: Field Study. Journal of Educational and Psychological Sciences, Bahrain University, 8(2), 235-236.

Ali, A. R., Endut, A., \& Embong, R. (2017). Investigating the Environmental Awareness Level of Secondary School Students: Effects of Race, School Type, and Location. Journal of Science and Technology, 9(4), 30-36. Retrieved https://publisher.uthm. edu.my/ojs/index.php/JST/article/view/ 2055

Altin, A., Tecer, S., Tecer, L., Altin, S., \& Kahraman, B. (2014). Environmental awareness level of secondary school students: a case study in Balıkesir (Türkiye). ProcediaSocial and Behavioural Sciences, 141, 1208-1214. http://doi.org/10.1016/j.sbspro. 2014.05.207

Alutaibi, N. (2003). The environmental awareness amongst female students at Umm Al-qura university from an Islamic perspective. Unpublished M.A. thesis, Umm Al-Qura University, Saudi Arabia.

Alutaibi, S. (2006). The dangers of Pollution Inside Houses: A social descriptive analytical study to a sample of ladies in Riyadh. Unpublished M.A. thesis, King Saud University, Saudi Arabia.

Alzahrani, S. (2009). The degree of the awareness to the dangers of electronic waste among the secondary stage students in Makkah Al-Mukarramah (The Holy Capital). Unpublished M.A. thesis, Umm Al-Qura University, Saudi Arabia.

Awan, A., \& Wamiq, S. (2016). Relationship between Environmental Awareness and Green Marketing. Science International, 28(3), 2959-2963.

Ba-Boteen, H. (2002). The level of awareness of some environmental hazards among faculty of education girl students in the scientific sections, in Makkah Al-Mukarramah and Jeddah cities. Unpublished M.A. thesis, Umm Al-Qura University, Saudi Arabia.

Barhoum, W. (2012). The eight-grade students' acquisition level of the environmental problems included in their geography book content. Unpublished M.A. thesis, Islamic University, Gaza.

Bergman, B. G. (2016). Assessing impacts of locally designed environmental education projects on students' environmental attitudes, awareness, and intention to act. 
Environmental Education Research, 22, 480-503. http://doi.org/10.1080/13504622. 2014. 999225.

Braus, J., \& Wood, D. (1993). Environmental education in the schools: Creating a program that works. Peace Corps, Washington. D. C.

Cohen, S., \& Wingerd, D. (1993). Children and the environment. Ecological awareness among pre-school children. Environment and Behaviour. 25(1), 103-120. http://doi.org/10.1177/0013916593251005

Goodall, S. (Ed.). (2018). Developing environmental education in the curriculum. London: Routledge.

Hameed, I. (2003). The effectiveness of out-of-door activities on the development of environmental awareness among sixth grade female students in Jeddah city. Unpublished M.A. thesis, Umm Al-Qura University, Saudi Arabia.

Hammami, M. B. A., Mohammed, E. Q., Hashem, A. M., Al-Khafaji, M. A., Alqahtani, F., Alzaabi, S., \& Dash, N. (2017). Survey on awareness and attitudes of secondary school students regarding plastic pollution: implications for environmental education and public health in Sharjah city, UAE. Environmental Science and Pollution Research, 24(8), 20626-20633. http://doi.org/10.1007/s11356-017-9625-x

Horka, H., \& Vystričil Markova, P. (2013). From Environmental Education to Biophiled Orientation of Education. Procedia-Social and Behavioural Sciences, 89, 328-331. http://doi.org/10.1016/j.sbspro.2013.08.855

Huang, T. C., Chen, C. C., \& Chou, Y. W. (2016). Animating eco-education: To see, feel, and discover in an augmented reality-based experiential learning environment. Computers \& Education, 96, 72-82. https://doi.org/10.1016/j.compedu.2016.02. 008

Johnston, H. (2012). Developing sustainable business and education partnerships with a positive impact on America's youth. Retrieved http://gearup.ous.edu/sites/default/files/ Research-Briefs/ResearchBriefSpiralCurriculum.pdf.

Kelder, S. H., Hoelscher, D., \& Perry, C. L. (2015). How individuals, environments, and health behaviours interact. In K. Glanz., B. Rimer., \& K. Viswanath (Eds.), Health behaviour: Theory, research, and practice (pp.159-182). San Francisco, CA: JosseyBass.

Kodama, T. (2017). Environmental education in formal education in Japan. Japanese Journal of Environmental Education, 26, 4 21-26. https://doi.org/10.5647/jsoee. $26.4 \_21$

Komane, F. (2005). The assessment of environmental awareness of the secondary school learners in the Mabopane district. M.A. Thesis, North-West University, South Africa.

Leeming, F., Dwyer, W., \& Bracken, B. (1995). Children's environmental attitude and knowledge scale: construction and validation. The Journal of Environmental Education. 26(3), 22-31. https://doi.org/10.1080/00958964.1995.9941442

Leigland, S. (2011). Beyond freedom and dignity at 40: Comments on behavioural science, the future, and chance (2007). The Behaviour Analyst, 34 (2), 283-295. https://doi.org/10.1007/BF03392258

Maravić, M., Cvjetićanin, S., \& Ivković, S. (2014). Level of environmental awareness of students in republic of Serbia. World Journal of Education, 4(3), 13. https://doi.org/10.5430/wje.v4n3p13

Mcgonigle-Chalmers, M. (2015). Understanding Cognitive Development. London: SAGE Publications.

Musser, L., \& Diamond, K. (1999). The children's attitudes toward the environment scale for preschool children. Journal of Environmental Education, 30(2), 23-31. https://doi.org/10.1080/00958969909601867

Musser, L., \& Malkus, A. (1994). The children's attitudes toward the environment scale. The Journal of Environmental Education. 25(3), 22-26. 
Mwendwa, B. (2017). Learning for sustainable development: Integrating environmental education in the curriculum of ordinary secondary schools in Tanzania. Journal of Sustainability Education, 12. https://doi.org/10.25073 /0866-773X/65

Oxford Dictionary. (2013). Oxford Advanced Learner's Dictionary. Retrieved http://oald8. oxfordlearnersdictionaries.com/dictionary/awareness.

Reed, J., Van Vianen, J., Deakin, E. L., Barlow, J., \& Sunderland, T. (2016). Integrated landscape approaches to managing social and environmental issues in the tropics: learning from the past to guide the future. Global change biology, 22, 25402554. https:// doi.org/10.1111/gcb.13284

Reid, I., \& Sa'di, I. (1997). An Arabic and English environmental attitudes scale for primary school children. Collected Original Resources in Education. 21(3), Fiche 1 A05.

Ryan, A., \& Spash, C. (2012). The awareness of consequences scale: an exploration, empirical analysis, and reinterpretation. Journal of Applied Social Psychology, 42(10), 2505-2540. https:// doi.org/10.1111/j.1559-1816.2012.00951.x

Sáez-López, J. M., Román-González, M., \& Vázquez-Cano, E. (2016). Visual programming languages integrated across the curriculum in elementary school: A two-year case study using "Scratch" in five schools. Computers \& Education, 97, 129-141. https:// doi.org/10.1016/j.compedu.2016.03.003

Shernoff, D. J., Kelly, S., Tonks, S. M., Anderson, B., Cavanagh, R. F., Sinha, S., \& Abdi, B. (2016). Student engagement as a function of environmental complexity in high school classrooms. Learning and Instruction, 43, 52-60. https://doi.org/10.1016/ j.learninstruc.2015.12.003

Singseewo, A. (2011). Awareness of environmental conservation and critical thinking of the undergraduate students. European Journal of Social Sciences, 25(1), 136-144.

Subbarini, M. (1989). Attitudes of Jordanian elementary school pupils towards the environment. International Journal of Environmental Education and Information. 8(3), $157-164$.

UNESCO. (1978). Intergovernmental conference on environmental education: Tbilisi (USSR), Final Report. Paris: Author.

Uzun, F. V., \& Keles, O. (2012). The effects of nature education project on the environmental awareness and behaviour. Procedia-Social and Behavioural Sciences, 46, 2912-2916. https://doi.org/10.1016/j.sbspro.2012.05.588 